\title{
Icodextrin Solution
}

National Cancer Institute

\section{Source}

National Cancer Institute. Icodextrin Solution. NCI Thesaurus. Code C119953.

An isosmotic solution containing icodextrin, a starch-derived, water-soluble glucose polymer, used in peritoneal dialysis and for the prevention of adhesion after surgery. Due to its iso-osmotic nature and inability to cross the peritoneal membrane, the icodextrin solution, upon administration into the peritoneal cavity, is able to exert osmotic pressure. This allows for the removal of excess fluids and waste products in dialysis patients. In addition, icodextrin can provide a barrier between tissue surfaces when administered during surgery. This physically separates tissues, prevents adhesion after surgery and promotes wound healing. 